\title{
Cationic Liposomes Target Angiogenic Endothelial Cells in Tumors and Chronic Inflammation in Mice
}

\author{
Gavin Thurston, John W. McLean, Michael Rizen, ${ }^{*}$ Peter Baluk, Amy Haskell, Thomas J. Murphy, Douglas Hanahan, ${ }^{\star}$ \\ and Donald M. McDonald \\ Department of Anatomy and Cardiovascular Research Institute, and *Department of Biochemistry and Biophysics and Hormone \\ Research Institute, University of California, San Francisco, California 94143
}

\begin{abstract}
This study sought to determine whether angiogenic blood vessels in disease models preferentially bind and internalize cationic liposomes injected intravenously. Angiogenesis was examined in pancreatic islet cell tumors of RIP-Tag2 transgenic mice and chronic airway inflammation in Mycoplasma pulmonis-infected $\mathrm{C} 3 \mathrm{H} / \mathrm{HeNCr}$ mice. For comparison, physiological angiogenesis was examined in normal mouse ovaries. We found that endothelial cells in all models avidly bound and internalized fluorescently labeled cationic liposomes (1,2-dioleoyl-3-trimethylammonium-propane [DOTAP]/cholesterol or dimethyldioctadecyl ammonium bromide [DDAB]/cholesterol) or liposome-DNA complexes. Confocal microscopic measurements showed that angiogenic endothelial cells averaged 15-33-fold more uptake than corresponding normal endothelial cells. Cationic liposome-DNA complexes were also avidly taken up, but anionic, neutral, or sterically stabilized neutral liposomes were not. Electron microscopic analysis showed that $32 \%$ of goldlabeled liposomes associated with tumor endothelial cells were adherent to the luminal surface, $53 \%$ were internalized into endosomes and multivesicular bodies, and $15 \%$ were extravascular $20 \mathrm{~min}$ after injection. Our findings indicate that angiogenic endothelial cells in these models avidly bind and internalize cationic liposomes and liposome-DNA complexes but not other types of liposomes. This preferential uptake raises the possibility of using cationic liposomes to target diagnostic or therapeutic agents selectively to angiogenic blood vessels in tumors and sites of chronic inflammation. (J. Clin. Invest. 1998. 101:1401-1413.) Key words: angiogenesis - blood vessels - cancer - endosomes - gene therapy
\end{abstract}

\section{Introduction}

Angiogenesis is a consistent feature of tumors and chronic inflammation. Indeed, the growth of tumors and the perpetuation of chronic inflammation may depend upon angiogenesis

Address correspondence to Gavin Thurston, Department of Anatomy, Box 0452, 505 Parnassus, Rm. 850-HSW, University of California, San Francisco, CA 94143-0452. Phone: 415-476-2118; FAX: 415476-4845; E-mail: gavint@itsa.ucsf.edu

Received for publication 18 June 1997 and accepted in revised form 27 January 1998.

J. Clin. Invest.

(C) The American Society for Clinical Investigation, Inc. 0021-9738/98/04/1401/13 \$2.00

Volume 101, Number 7, April 1998, 1401-1413

http://www.jci.org
$(1,2)$. Therefore, one strategy of treating these diseases is to inhibit new vessel growth (2-4). The identification of distinctive features of angiogenic endothelial cells could make it possible to target therapeutic agents selectively to angiogenic vessels. Studies showing that angiogenic endothelial cells have distinctive adhesion molecules (5), receptors (6), oligosaccharides (7), or other cell surface proteins (4) provide promise that selective delivery to these cells is feasible. Indeed, the utility of these features to target agents to angiogenic blood vessels has been demonstrated in specific disease models (8-10).

However, angiogenesis is not a singular process, and newly formed blood vessels may have very different properties. For example, at least two types of angiogenesis may contribute to vessel growth in tumors. One process involves sprouting and migration of endothelial cells from existing capillaries (sprouting angiogenesis [2]), while the other involves the creation of multiple new vessels from existing ones that are divided by intraluminal septae or pillars (intussusceptive angiogenesis [11]). The anatomic location of tumors or exogenous growth factors can influence the physiological properties of the resultant vessels $(12,13)$. In addition, angiogenic vessels at sites of inflammation can vary with different stimuli and in different animal strains or species (14-17).

Cationic liposomes have been used to deliver DNA for gene therapy in vivo (18-20). When cationic liposome-DNA complexes are injected intravenously into normal mice, transgene expression occurs in specific organs including the lung and heart $(18,20,21)$. This organ-specific pattern of transgene expression is partly related to the pattern of endothelial cell uptake of cationic liposomes. We have found that cationic liposome-DNA complexes injected intravenously into normal mice are taken up by endothelial cells in an organ- and vesselspecific pattern (21). Endothelial cells in the lung and anterior pituitary avidly internalize cationic liposome-DNA complexes into endosomes, while endothelial cells in the brain and posterior pituitary show little or no uptake (21).

Liposome-mediated gene therapy is an attractive approach for diseases dependent on angiogenesis. Noncationic liposomes have been used to deliver therapeutic drugs such as doxorubicin to tumors (22). However, most studies have sought to exploit the increased macromolecular permeability of tumor vessels to deliver liposome-encapsulated agents preferentially to the tumor interstitium (23-26). This approach relies on gradual, passive accumulation of the liposome-encapsulated therapeutic agent in tumors, generally requiring 1-24 h $(24,25,27)$. Sterically stabilized liposomes with prolonged circulation times have been developed for this purpose $(23,24)$. In contrast, cationic liposomes are rapidly cleared from the circulation by the liver, spleen, and lung $(21,28,29)$ and have not been used with the intent of targeting agents to endothelial cells in tumors and other sites of angiogenesis.

In view of the finding that cationic liposomes are taken up by endothelial cells in an organ-specific and vessel-specific pat- 
tern in normal mice (21), we sought to determine whether angiogenic blood vessels that form in solid tumors or chronic inflammatory diseases are sites of preferential uptake. Because of the differences in angiogenic blood vessels in different disease models, we examined two models of angiogenesis in tumors and another model involving chronic airway inflammation. These disease models in mice were compared with physiological angiogenesis in the normal mouse ovary.

The specific aims of our study were to: $(a)$ compare the amount of cationic liposomes taken up by tumor vessels with that taken up by corresponding normal vessels; $(b)$ identify the locations of cationic liposomes in the wall of tumor vessels, and determine the mechanism of entry into the endothelial cells; $(c)$ compare the uptake by tumor vessels with that by vessels at sites of chronic airway inflammation and normal ovarian follicles and corpora lutea; $(d)$ determine the specificity of uptake by comparing cationic, anionic, neutral, and sterically stabilized neutral liposomes as well as cationic liposome-DNA complexes; and (e) determine whether cationic liposomes can be used to deliver macromolecules, including DNA, preferentially to angiogenic endothelial cells.

We examined the uptake of fluorescently labeled cationic liposomes and liposome-DNA complexes by vascular endothelial cells in transgenic mice with solid tumors, in mice with chronic airway infection due to Mycoplasma pulmonis, and in normal mice. At $20 \mathrm{~min}$ or $4 \mathrm{~h}$ after red fluorescent liposomes were injected intravenously, the vasculature was stained by perfusion of a green fluorescent lectin, and the location and amount of liposomes in tissue whole mounts were determined by fluorescence and confocal microscopy. The specific cell associations and the intracellular distribution of the liposomes were determined by transmission electron microscopy.

\section{Methods}

\section{Murine models of angiogenesis}

Tumor models in transgenic mice. We used two tumor models in transgenic mice in which angiogenesis has been well characterized $(30,31)$. In the first model, designated RIP-Tag2, expression of the SV-40 virus large $\mathrm{T}$ antigen (Tag) ${ }^{1}$ oncogene is driven by the $5^{\prime}$ flanking region of the rat insulin gene including the promoter (RIP). When inserted into the murine genome, this construct induces expression of $\mathrm{T}$ antigen specifically in the $\beta$ cells of pancreatic islets. One important attribute of this model is that various stages of tumor development, and therefore various stages of angiogenesis, are present concurrently in each RIP-Tag2 mouse. Although all of the 300-400 islets express T antigen, the islets initially develop normally. However, about half of the islets become hyperplastic by $6 \mathrm{wk}$ of age, and a small proportion develop into tumors by $12 \mathrm{wk}$. Tumorigenesis appears to be closely linked with the onset of angiogenesis (32). RIP-Tag2 C57BL/6 mice were bred and raised under barrier conditions in the transgenic mouse facilities at University of California, San Francisco. Mice were genotyped at weaning ( $3 \mathrm{wk}$ ) by PCR on tail-tip DNA using primers for $\mathrm{T}$ antigen (33). Nontransgenic littermates were used as controls. Male and female mice were used at 9-11 wk of age.

In the other tumor model, designated K14-HPV16, the oncogene from the human papilloma virus (HPV) is driven by a region of the keratin 14 (K14) promoter $(34,35)$. In these transgenic mice, viral oncogene expression occurs in epidermal cells. All of the mice develop

1. Abbreviations used in this paper: DOTAP, 1,2-dioleoyl-3-trimethylammonium-propane; HPV, human papilloma virus; K14, keratin 14; RIP, rat insulin promoter; Tag, $\mathrm{T}$ antigen. skin dysplasia accompanied by angiogenesis, and a small proportion develop skin tumors (35).

Chronic airway inflammation model. Angiogenesis associated with chronic airway inflammation was studied in $\mathrm{C} 3 \mathrm{H} / \mathrm{HeNCr}$ mice infected with $M$. pulmonis, which afforded the opportunity to examine a type of vascular remodeling different from that in RIP-Tag2 or K14-HPV16 tumors. Previous studies have shown that M. pulmonis infection in the airways of F344 rats causes chronic inflammation with angiogenesis, characterized by extensive proliferation of mucosal blood vessels $(14,16)$. Recently, we characterized the vascular remodeling in the airways of $\mathrm{C} 3 \mathrm{H} / \mathrm{HeNCr}$ mice, a strain known to be sensitive to M. pulmonis (36). Airway blood vessels of F344 rats and $\mathrm{C} 3 \mathrm{H} / \mathrm{HeNCr}$ mice infected with $M$. pulmonis are similar in that both have normal baseline permeability (with no intervention apart from the infection) but both have exaggerated leakiness after exposure to substance $\mathrm{P}(14,16){ }^{2}$ However, one difference is that airway blood vessels in infected $\mathrm{C} 3 \mathrm{H} / \mathrm{HeNCr}$ mice become conspicuously enlarged without an increase in vessel number or length (17). Nonetheless, this enlargement is accompanied by a doubling of the number of endothelial cells, consistent with it being a form of angiogenesis (17). Although the terminology concerning angiogenesis is not consistent in the literature, vessel enlargement has been reported in another model of angiogenesis associated with inflammation (15) and may explain the presence of large, dilated, congested blood vessels in the airways of people with asthma (37-40).

Pathogen-free, 8 wk-old, male and female $\mathrm{C} 3 \mathrm{H} / \mathrm{HeNCr}$ mice (Charles River Laboratories, Hollister, CA) were inoculated intranasally with $3 \times 10^{4} \mathrm{cfu}$ of $M$. pulmonis (strain $5782 \mathrm{C}-\mathrm{UAB} \mathrm{CT}_{7}$; obtained from Dr. J. Russell Lindsey, University of Alabama, Birmingham, AL) in a volume of $50 \mu \mathrm{l}$ after anesthesia $(87 \mathrm{mg} / \mathrm{kg}$ ketamine and $13 \mathrm{mg} / \mathrm{kg}$ xylazine intraperitoneally). Pathogen-free mice were used as controls. Infected and control mice were caged separately under barrier conditions for $4 \mathrm{wk}$. Antibody titers to M. pulmonis were measured in serum obtained from control and infected mice at the time of the experiment (Microbiological Associates, Bethesda, MD). All of the infected mice had significant titers to M. pulmonis, but none of the pathogen-free mice had measurable titers.

Normal ovarian angiogenesis model. Ovaries were examined in normal female C57BL/6 mice at 9 wk of age with a focus on the angiogenesis associated with mature antral follicles and developing corpora lutea $(41,42)$.

Animals were housed in the University of California, San Francisco Animal Care Facility and handled in accordance with the procedures of the UCSF Committee on Animal Research.

\section{Fluorescent liposomes and liposome-DNA complexes}

Cationic liposomes were prepared with 55 mole\% 1,2-dioleoyl-3-trimethylammonium-propane (DOTAP) and 45 mole \% cholesterol (both Avanti Polar Lipids, Alabaster, AL). Dimethyldioctadecyl ammonium bromide (DDAB; Sigma Chemical Co., St. Louis, MO) was used in place of DOTAP in some experiments. Neutral liposomes were prepared with 55 mole \% egg yolk phosphatidylcholine (Avanti Polar Lipids) and 45 mole \% cholesterol. Anionic liposomes were prepared with 33 mole \% brain phosphatidylserine (Avanti Polar Lipids), 33 mole\% egg yolk phosphatidylcholine, and 34 mole \% cholesterol. Sterically stabilized liposomes were prepared with $50 \mathrm{~mole} \%$ egg yolk phosphatidylcholine, 5 mole\% PEG2000 DOPE (1,2-dioleoyl$s n$-glycero-3-phosphoethanolamine- $N$-(poly(ethylene glycol) 2000); Avanti Polar Lipids), and 45 mole\% cholesterol.

2. Evans blue concentrations in the trachea of pathogen-free $\mathrm{C} 3 \mathrm{H} /$ $\mathrm{HeNCr}$ mice were $17.4 \pm 1.8 \mathrm{ng} / \mathrm{mg}$ wet weight under baseline conditions and $16.2 \pm 1.7 \mathrm{ng} / \mathrm{mg}$ after substance $\mathrm{P}(5 \mu \mathrm{g} / \mathrm{kg}$, i.v. $)$, whereas the corresponding values in $M$. pulmonis-infected mice 4 wk after inoculation were $19.4 \pm 3.7$ and $33.1 \pm 3.5 \mathrm{ng} / \mathrm{mg}$ (Baluk, P., G. Thurston, T.J. Murphy, and D.M. McDonald, unpublished observations). 
Liposomes were prepared by rotary evaporation of lipid solutions in chloroform, at $42^{\circ} \mathrm{C}$, under vacuum, in a stream of argon. The flask containing the thin lipid film was then placed under high vacuum for $1 \mathrm{~h}$ to remove traces of solvent. Sufficient $5 \%$ glucose was added to the flask to give a $10 \mathrm{mM}$ total lipid concentration, and the mixture was incubated at $42^{\circ} \mathrm{C}$ for $1 \mathrm{~h}$ with occasional vortexing. The suspension was then sonicated by immersion of the flask in an ultrasonic bath (Laboratory Supplies Co., Hicksville, NY) for $20 \mathrm{~min}$ to produce small unilamellar vesicles. These were filtered though a sterile $0.2-\mu \mathrm{m}$ Nalgene syringe filter and stored at $4^{\circ} \mathrm{C}$. Liposomes were prepared and stored under argon.

The fluorescent phospholipid Texas red-DHPE (1,2-dihexadecanoyl-sn-glycero-3-phosphoethanolamine; Molecular Probes, Eugene, OR) was incorporated during liposome synthesis to give a final fluorophore concentration of $0.25-1.0 \mathrm{~mole} \%$. For transmission electron microscopy, the electron-dense lipid Nanogold 1,2-dipalmitoylsn-glycero-3-phosphoethanoloamine (Nanoprobes, Stony Brook, NY) was incorporated synthetically into DOTAP/cholesterol liposomes to give a final concentration of $0.2 \mathrm{~mole} \%$. In some liposomes, lysinefixable fluorescent Texas red-dextran MW $3000(10 \mathrm{mg} / \mathrm{ml}$; Molecular Probes) was encapsulated by addition to the $5 \%$ glucose used for resuspension. After sonication, the liposomes were separated from free dextran by column chromatography on Sephadex G-75 superfine (Pharmacia, Biotech, Piscataway, NJ). The columns were preloaded with DOTAP/cholesterol liposomes and washed thoroughly with 5\% glucose before loading the Texas red dextran liposomal mixture. Liposomes encapsulating Texas red dextran eluted in the column void volume when the column was flushed with $5 \%$ glucose.

Cationic liposome-DNA complexes were prepared by the rapid addition of $80 \mu \mathrm{g}$ of plasmid DNA in 5\% glucose to an equal volume of liposomes $(1,920 \mathrm{nM}$ total lipid) in $5 \%$ glucose. Plasmid DNA (5435 bp) was isolated from Escherichia coli SURE (Stratagene, La Jolla, CA) and purified by alkaline lysis and anion exchange chromatography (Qiagen, Chatsworth, CA). Fluorescently labeled DNA was prepared by the enzymatic addition of Cy3-labeled nucleotides to the termini of linearized DNA. In brief, plasmid DNA was digested with Bsp1286I (New England Biolabs, Beverly, MA) to give five fragments ranging in size from 85 to $1323 \mathrm{bp}$. Terminal deoxynucleotidyl transferase (Promega Corp., Madison, WI) was used to catalyze the addition of Cy3-dCTP residues (Amersham Life Science, Inc., Arlington Heights, IL) to the 3' termini of the DNA fragments. Labeled DNA was purified by Qiagen column chromatography as above. Labeled and unlabeled DNA fragments migrated indistinguishably when analyzed by agarose gel electrophoresis.

\section{Fluorescence and confocal microscopy}

Liposomes (1,440 $\mathrm{nM}$ total lipid in 5\% glucose) or liposome-DNA complexes $(60 \mu \mathrm{g}$ plasmid DNA and $1,440 \mathrm{nM}$ total lipid in $5 \%$ glucose) were injected via a tail vein in a volume of $0.1-0.2 \mathrm{ml}$. At 15 or $235 \mathrm{~min}$ after the injection, the mice were anesthetized by intraperitoneal injection of pentobarbital sodium $50 \mathrm{mg} / \mathrm{kg}$ (Abbott Laboratories, North Chicago, IL) and supplemented as necessary. In some mice, Monastral blue $(30 \mathrm{mg} / \mathrm{kg}$ in $0.1 \mathrm{ml})$, instead of the liposomes, was injected via a tail vein $5 \mathrm{~min}$ before fixation to assess endothelial permeability (14). Blood $(0.2 \mathrm{ml})$ was drawn from the right jugular vein of infected mice and their pathogen-free controls into a heparinized syringe for M. pulmonis serology. At $20 \mathrm{~min}$ or $4 \mathrm{~h}$ after injection of liposomes or liposome-DNA complexes, the vasculature was fixed by perfusion of $1 \%$ paraformaldehyde in PBS, $\mathrm{pH} 7.4$, for 3 min at $120 \mathrm{mmHg}$, and stained by perfusion of fluorescein Lycopersicon esculentum lectin (Vector, Burlingame, CA) (21). Tracheas were opened along the ventral midline and mounted mucosal surface up in Vectashield (Vector). The pancreas was spread, partially dissected along the main ducts to expose the islets and tumors, and mounted whole. Large tumors were cut into thick sections $(100 \mu \mathrm{m})$ with a Vibratome (Technical Products International, St. Louis, MO). Ovaries were cut longitudinally with a razor blade into three to four sections and mounted. Tissues were kept refrigerated and examined within $24 \mathrm{~h}$ using a Zeiss Axiophot fluorescence microscope with Fluar objectives or a Zeiss LSM 410 confocal microscope equipped with a kryptonargon laser and optimized photomultiplier tubes. Extravasated Monastral blue was viewed in cleared whole mounts of the pancreas or trachea using bright-field optics (14). Images were recorded on Kodak Ektachrome film (ASA 400) or as digital confocal image files.

\section{Transmission electron microscopy}

Electron-dense lipid Nanogold 1,2-dipalmitoyl-sn-glycero-3-phosphoethanoloamine-DOTAP/cholesterol liposomes or unlabeled liposomes $(1,440 \mathrm{nM}$ total lipid in 5\% glucose) were injected via tail vein in a volume of $0.1-0.2 \mathrm{ml}$. At $20 \mathrm{~min}$ after the injection, tissues were fixed by vascular perfusion of $3 \%$ glutaraldehyde in cacodylate buffer, $\mathrm{pH} 7.1$, for $10 \mathrm{~min}$ at $120 \mathrm{mmHg}$, removed, and fixed overnight at $4^{\circ} \mathrm{C}(21)$. Intercartilaginous and posterior membrane regions of tracheas from M. pulmonis-infected and pathogen-free mice were isolated with a razor blade. Pancreatic islets and tumors were removed and sectioned (80-100 $\mu \mathrm{m}$ thick) with a tissue chopper (Sorvall, Newtown, CT).

To silver-enhance the gold-labeled liposomes, tissue sections were treated with glycine (50 mM in PBS, $\mathrm{pH} 7.4)$, rinsed with Hepes buffer $(50 \mathrm{mM})$, pH 5.8, containing sucrose $(200 \mathrm{mM})$, stained with a LI Silver enhancement kit (Nanoprobes) (43) using a development time of $20 \mathrm{~min}$, fixed with sodium thiosulfate $(250 \mathrm{mM})$ in Hepes buffer $(20 \mathrm{mM}), \mathrm{pH} 7.4$, and rinsed with Hepes buffer $(50 \mathrm{mM}), \mathrm{pH} 5.8$, containing sucrose $(200 \mathrm{mM})$.

Tissue sections were postfixed in osmium tetroxide in one of two ways: silver-enhanced tissues were treated with $0.1 \%$ osmium tetroxide in $100 \mathrm{mM}$ cacodylate buffer, $\mathrm{pH} 7.4$, for $30 \mathrm{~min}$ at $4^{\circ} \mathrm{C}$, while nonenhanced tissues were treated with $2 \%$ osmium tetroxide in the same buffer for $14-18 \mathrm{~h}$ at $4^{\circ} \mathrm{C}$. After treatment with uranyl acetate $(2 \%$ for $48 \mathrm{~h}$ at $37^{\circ} \mathrm{C}$ ), tissues were embedded in epoxy resin (LX112; Ladd Research, Burlington, VT), thin-sectioned (Ultracut; Leica, Deerfield, IL), and stained with lead citrate. The specificity of the silver enhancement step was tested by omitting the silver enhancement, osmium, or uranyl acetate staining. Sections $80 \mathrm{~nm}$ in thickness were examined with a Zeiss EM-10 electron microscope.

\section{Quantitation of uptake of fluorescent and} gold-labeled liposomes

To quantify liposome uptake, a series of 10-12 confocal images separated by $2.5 \mu \mathrm{m}$ in the focal $(z)$ axis was collected in both the fluorescein and Texas red channels using a $\times 20$ NA 0.6 lens (Zeiss) and standardized settings of the confocal pinhole size, photomultiplier tube gain, and laser power. Images were recorded of vessels in tumors $>1 \mathrm{~mm}$ in diameter from RIP-Tag2 mice and of mucosal vessels across the cartilage rings in tracheas of $M$. pulmonis-infected mice. Corresponding images were collected from normal islets of wild-type mice and tracheas of pathogen-free mice. Projections, showing the vessel images (fluorescein-lectin) and liposome images (Texas redlipid) separately, were generated from the image series. The confocal software was used to outline regions $\sim 200 \mu \mathrm{m}^{2}$ on the vessel images, then the average fluorescence value of the pixels within the corresponding regions of the liposome images was measured. The pixel fluorescence values, ranging from 0 (dark) to 255 (saturated), represent the digitized output from the confocal photomultiplier tubes. Background intensity was determined by measuring fluorescence in selected regions adjacent to the vessels and was subtracted from the measured intensities. Measurements were made on 25 vessels per trachea and 4 tracheas per group $(n=4)$, or on 3 vessels per islet or tumor, 10 islets or tumors per mouse, and 4 mice per group $(n=4)$.

Silver-enhanced, gold-labeled liposomes associated with endothelial cells in RIP-Tag2 tumors were photographed by electron microscopy and printed at $\times 56,000$. The locations of 400 sequentially photographed liposomes having two to four silver grains were classified as located on the luminal endothelial cell surface, inside an endothelial cell, or near the abluminal surface of the endothelium. Liposomes on the luminal endothelial cell surface were further classified as associ- 

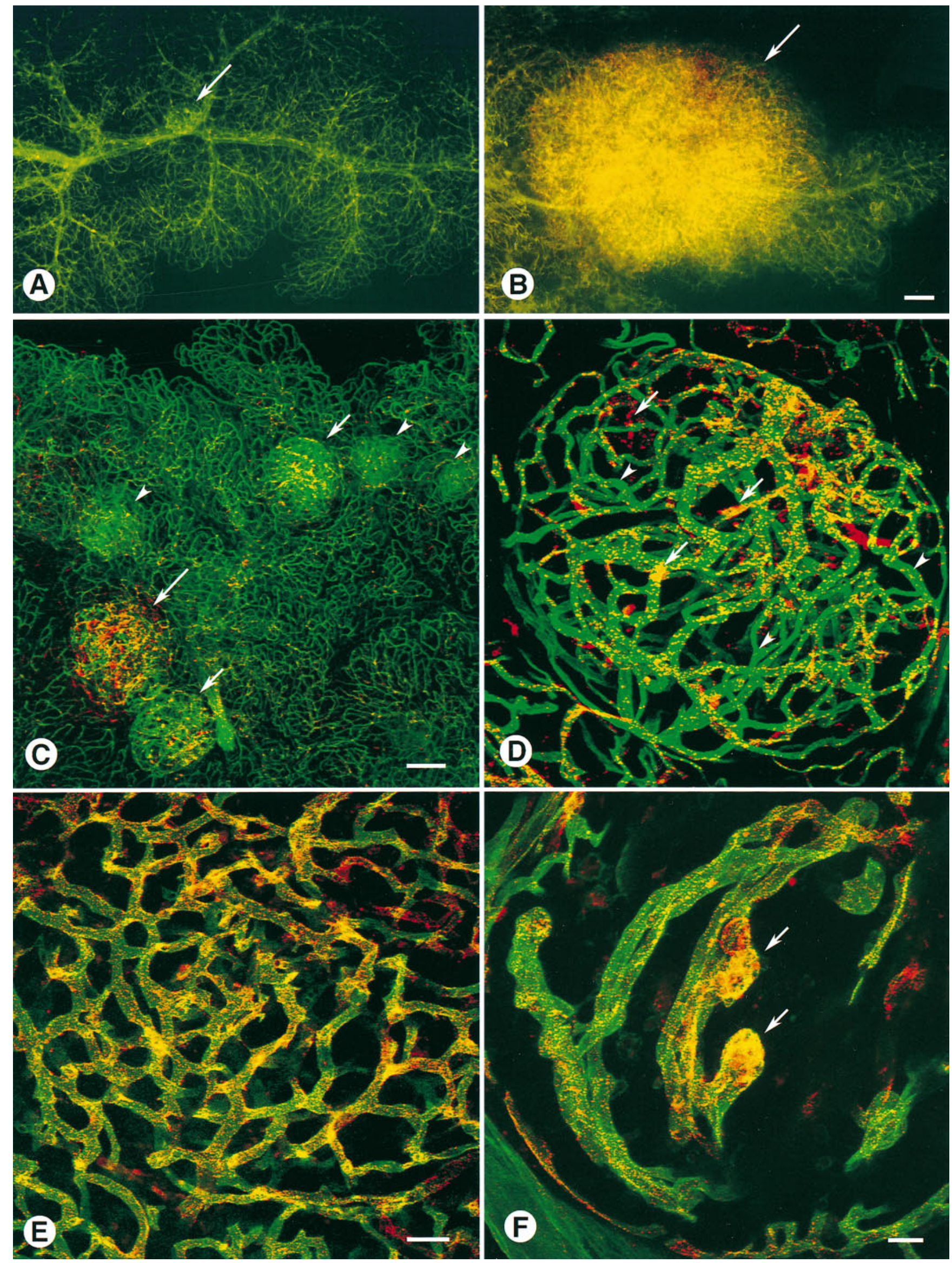
ated with fenestrae, membrane invaginations (caveolae or coated pits), or other regions of membrane. Liposomes inside an endothelial cell were further classified as in small vesicles, larger organelles resembling multivesicular bodies, or complex structures composed of multiple interconnected vesicles. Liposomes near the abluminal surface of the endothelium were further classified as associated with (within $100 \mathrm{~nm}$ of) fenestrae, associated with coated membrane invaginations or caveolae, or not associated with endothelial cells. The total length of luminal endothelial cell surface and the proportion of membrane composed of fenestrae were measured on electron micrographs at $\times 56,000$ using a digitizing tablet (44).

\section{Statistical analysis}

Measurements are presented as mean \pm SE ( $n=4$ mice per group) unless otherwise indicated. Significance of differences between groups was assessed by unpaired Student's $t$ test. Differences with $P<0.05$ were considered significant.

\section{Results}

Avid association of cationic liposomes with tumor vessels. Pancreatic islets and tumors were readily seen by fluorescence microscopy after the vasculature was stained by perfusion of the green fluorescent lectin (Fig. 1, $A$ and $B$ ). In these preparations, the vasculature of normal nontransgenic islets had little or no Texas red fluorescence at $20 \mathrm{~min}$ or $4 \mathrm{~h}$ after injection of fluorescent-labeled DOTAP/cholesterol cationic liposomes (Fig. 1 A). By comparison, the vasculature of tumors in RIPTag2 mice had intense Texas red fluorescence at both time points (Fig. $1 B$ ). In addition to the avid uptake by tumor vessels, there was a normal pattern of uptake of the cationic liposomes by macrophages in the liver and spleen and by endothelial cells in the lung and certain other organs, as described previously (21).

Because tumorigenesis proceeds asynchronously among the 300-400 islets in the pancreas of RIP-Tag2 mice, various stages of tumor development could be compared in the same pancreas $(31,32)$. The intensity of Texas red fluorescence corresponded to the size of the islets or tumors (Fig. $1 C$ ). Normal-sized islets in RIP-Tag2 mice had little or no Texas red fluorescence, as in wild-type mice. However, vessels in enlarged (hyperplastic) islets had focal regions of red fluorescence (Fig. $1, C$ and $D$ ), and those in tumors had uniformly intense red fluorescence (Fig. $1 \mathrm{E}$ ). Many focal regions of red fluorescence in hyperplastic islets were associated with vessel protrusions that appeared to end blindly (Fig. $1 F$ ). The amount of Texas red fluorescence due to cationic liposomes in tumor vessels averaged 33 times that associated with corresponding vessels in wild-type mice (Fig. 2). Similarly, angiogenic blood vessels in

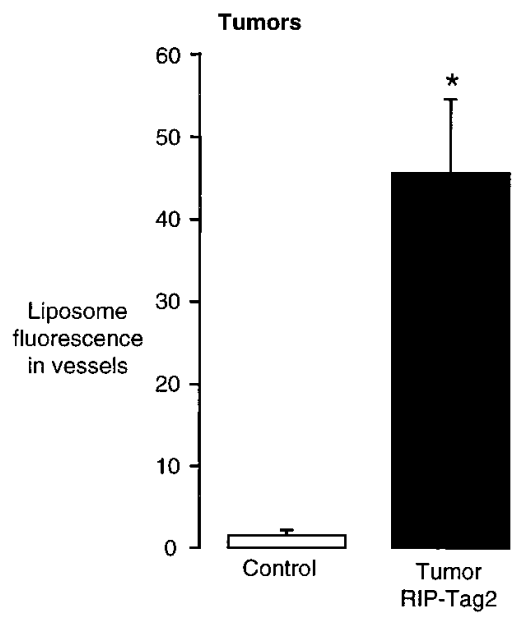

Figure 2. Amount of Texas red fluorescence in islet vessels in wildtype mice and tumor vessels in RIP-Tag2 mice $4 \mathrm{~h}$ after injection of Texas red-labeled cationic liposomes.

Fluorescence was measured on standardized confocal micrographs of 3 vessels per islet, 10 islets per mouse, 4 mice per group $(n=4)$. Fluorescence values represent digitized signal (0 to 255) from red channel photomultiplier tube. Values are mean \pm SE. *Significantly different from control value, $P<0.05$, unpaired Student's $t$ test.

regions of dysplastic skin of K14-HPV16 mice showed greater Texas red fluorescence than did vessels in normal skin.

Uptake and intracellular localization versus extravasation of liposomes by tumor vessels. Fluorescent liposomes in RIPTag2 tumors examined by confocal microscopy appeared to be closely associated with lectin-stained blood vessels. No Texas red fluorescence was seen in the surrounding tissue (Fig. 1, E and $F$ ), suggesting that the liposomes were associated with the endothelial cells or other components of the vessel wall. Little or no extravasated Monastral blue was found within tumors, but focal regions of extravasated Monastral blue were found on some vessels at the interface of tumors and the surrounding pancreatic tissue.

To determine whether the liposomes were taken up by endothelial cells, extravasated, or both, we obtained more detailed information on the location of the liposomes in RIP-Tag2 tumors by examining silver-enhanced, gold-labeled liposomes by electron microscopy. At $20 \mathrm{~min}$ after injection, liposomes were found on the luminal surface of the endothelium (Fig. 3, $A, C$, and $D$ ), inside endothelial cells (Fig. 3, $B$ and $D$ ), and on the abluminal side of the endothelium (Fig. $3 E$ ). Many liposomes on the luminal surface were associated with membrane invaginations (Fig. $3 A$ ) or fenestrae (Fig. $3 C$ ). Some liposomes were in coated invaginations of the plasma membrane or near caveolae. Most liposomes inside endothelial cells were in small vesicles or larger organelles resembling multivesicular bodies (Fig. 3, $B$ and $D$ ). Liposomes on the abluminal side of the en-

Figure 1. Fluorescence and confocal micrographs showing the vasculature of mouse pancreas after intravenous injection of Texas red-labeled cationic liposomes and vascular perfusion of fluorescein-labeled lectin. (A) Little fluorescence associated with cationic liposomes in islet (arrow) and acini of normal mouse pancreas, and $(B)$ abundant fluorescence in large tumor (arrow) in transgenic RIP-Tag2 mouse. Yellow color in tumor is due to colocalization of red and green fluorescence. $(C)$ Different stages of tumor development in pancreas of RIP-Tag2 mouse showing different amounts of cationic liposome fluorescence: weak red fluorescence in normal-sized islets (arrowheads), focal bright fluorescence in hyperplastic islets (short arrows), and more uniform bright fluorescence in small tumor (long arrow). (D) Hyperplastic islet with foci of bright fluorescence of cationic liposomes in some vessels (arrows) but not others (arrowheads). (E) Uniform bright fluorescence in vessels of large tumor similar to one in $B$; none is evident outside vessels. $(F)$ Higher magnification view of hyperplastic islet showing focal sites of liposome fluorescence associated with vessel protrusions that end blindly (arrows). No Texas red fluorescence visible outside vessels. Scale bars: $A$ and $B, 200$ $\mu \mathrm{m} ; C, 200 \mu \mathrm{m} ; D$ and $E, 50 \mu \mathrm{m} ; F, 20 \mu \mathrm{m}$. 

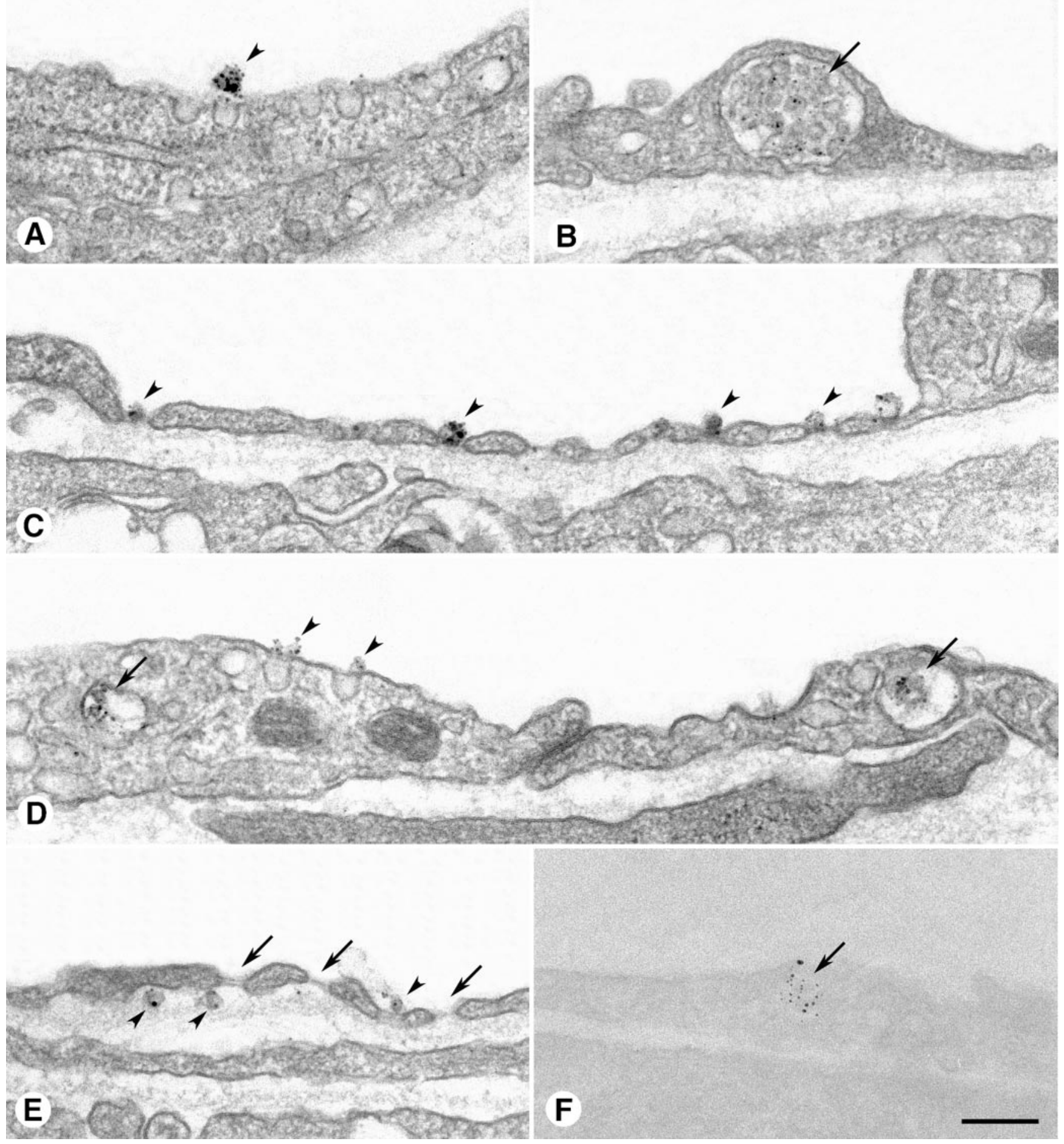

Figure 3. Electron micrographs of silver-enhanced, gold-labeled cationic liposomes in tumor vessels 20 min after injection into RIP-Tag2 mice. $(A)$ Clusters of silver grains (arrowhead) identifying liposomes near invagination of plasma membrane of endothelial cell. (B) Silver grains on liposomes (arrow) in multivesicular body in endothelial cell. (C) Silver grains on liposomes (arrowheads) on luminal surface of fenestrae. (D) Silver grains on liposomes near invaginations (arrowheads) on luminal plasma membrane of endothelial cell and in multivesicular bodies (arrows). Endothelial junction is closed. (E) Silver grains on liposomes (arrowheads) near endothelial fenestrae (arrows). Two liposomes are near abluminal surface of endothelium and one is on luminal surface near fenestrae. (F) Silver grains (arrow) associated with intracellular organelle in endothelial cell of tumor processed without uranyl acetate in block or lead citrate staining. Scale bar, $200 \mathrm{~nm}$. 


\begin{tabular}{|c|c|c|c|}
\hline Location & Number of liposomes & Percentage of group & Percentage of overall total \\
\hline \multicolumn{4}{|l|}{ Luminal surface of endothelium } \\
\hline Endothelial fenestrae & 65 & $51 \%$ & $17 \%$ \\
\hline Caveolae and coated invaginations & 21 & $17 \%$ & $5 \%$ \\
\hline Other regions of plasma membrane & 41 & $32 \%$ & $10 \%$ \\
\hline Group total & 127 & $100 \%$ & $32 \%$ \\
\hline \multicolumn{4}{|l|}{ Inside endothelial cells } \\
\hline Multivesicular bodies & 188 & $89 \%$ & $47 \%$ \\
\hline Small vesicles & 22 & $10 \%$ & $6 \%$ \\
\hline Complex vesicular structures & 2 & $<1 \%$ & $<1 \%$ \\
\hline Group total & 212 & $100 \%$ & $53 \%$ \\
\hline \multicolumn{4}{|l|}{ Abluminal surface of endothelium } \\
\hline Endothelial fenestrae & 29 & $48 \%$ & $7 \%$ \\
\hline Caveolae and coated invaginations & 20 & $33 \%$ & $5 \%$ \\
\hline Free in basement membrane & 12 & $20 \%$ & $3 \%$ \\
\hline Group total & 61 & $100 \%$ & $15 \%$ \\
\hline Overall total & 400 & & $100 \%$ \\
\hline
\end{tabular}

Values are the number of silver-enhanced, gold-labeled DOTAP/cholesterol cationic liposomes at each location, as determined in 49 sequential electron micrographs $(\times 56,000)$ of angiogenic blood vessels in tumors of a RIP-Tag2 mouse. Only liposomes that were associated with the tumor vasculature and had two or more silver grains were included. Tumors were fixed by vascular perfusion $20 \mathrm{~min}$ after injection of liposomes.

dothelium were confined to the basement membrane; many of these were near fenestrae (Fig. $3 E$ ). Silver particles on liposomes in specimens in which the uranyl acetate or lead citrate was omitted appeared identical to those in other preparations, but cellular morphology was indistinct (Fig. $3 F$ ).

The proportions of luminal, intracellular, and extravascular liposomes were determined from the distribution of silverenhanced gold-labeled liposomes in 49 sequential transmission electron micrographs of vessels in RIP-Tag2 tumors. Of the 400 tumor vessel-associated liposomes examined, 32\% were on the luminal surface of the endothelium, $53 \%$ were inside endothelial cells, and $15 \%$ were on the abluminal surface of the endothelium (Table I). Of the liposomes on the luminal surface, the largest proportion (51\%) was associated with endothelial fenestrae, even though the fenestrae constituted only $4 \%$ of the endothelial surface (137 fenestrae, with a total length of $7.4 \mu \mathrm{m}$, were found in a 184- $\mu \mathrm{m}$ length of endothelium). The remainder was associated with caveolae or coated invaginations $(17 \%)$ or with other regions of the plasma membrane (32\%). Of the liposomes inside endothelial cells, $89 \%$ were in multivesicular bodies, $10 \%$ were in small vesicles, and $\sim 1 \%$ were in complex structures composed of multiple interconnecting vesicles. Of the liposomes on the abluminal side of the endothelium, $47 \%$ were within $100 \mathrm{~nm}$ of fenestrae, $33 \%$ were near caveolae or coated invaginations of the abluminal plasma membrane, and $20 \%$ were located elsewhere in the endothelial basement membrane. No gaps were evident in the 11 endothelial cell junctions present in this sample.

Uptake of cationic liposomes by blood vessels in chronic inflammation. The vasculature of the tracheal mucosa of normal $\mathrm{C} 3 \mathrm{H} / \mathrm{HeNCr}$ mice had little Texas red fluorescence at $20 \mathrm{~min}$ or $4 \mathrm{~h}$ after injection of the cationic liposomes (Fig. $4 A$ ). In contrast, these vessels in mice infected with $M$. pulmonis for 4 wk had conspicuous Texas red fluorescence (Fig. 4, $B$ and $C$ ). At $20 \mathrm{~min}$ after injection, patches of Texas red fluorescence coated the luminal surface of some vessels (Fig. $4 \mathrm{~B}$ ), whereas at $4 \mathrm{~h}$ the fluorescence was in the form of discrete dots (Fig. $4 \mathrm{C}$ ). Some of the red dots were slightly beneath the luminal surface, consistent with an intracellular location (Fig. $4 \mathrm{D}$ ), but extravasation could not be excluded. However, electron microscopic examination showed that liposomes were located on the luminal plasma membrane (Fig. 5, $A$ and $B$ ), in coated (Fig. $5 B$ ) and uncoated membrane invaginations, and in intracellular vesicles and multivesicular bodies similar to those in the tumor vessels. No endothelial fenestrations were found in these vessels in a total of $121 \mu \mathrm{m}$ of endothelial cell surface examined in 29 electron micrographs.

Because the vasculature of the tracheal mucosa of infected $\mathrm{C} 3 \mathrm{H} / \mathrm{HeNCr}$ mice had a simple architecture, it was possible to identify the vessel components and determine that most of the uptake was in enlarged vessels in the position of postcapillary venules and collecting venules. These remodeled vessels are very conspicuous after $M$. pulmonis infection (17). The average amount of liposome fluorescence associated with the remodeled vessels in infected tracheas was 15 -fold that of corresponding normal vessels (Fig. 6). A difference of 100-fold was found in some vessels.

Uptake of cationic liposomes by angiogenic vessels in the ovary. Intense Texas red fluorescence was found in blood vessels around large ovarian follicles and in newly formed corpora lutea (Fig. $4 E$ ). The Texas red fluorescence was confined to the plexus of vessels surrounding large antral follicles (Fig. 4 $F$ ), while none was observed inside follicles. Vessels in large, rapidly growing corpora lutea also had intense punctate Texas red fluorescence (Fig. $4 F$ ), but those in smaller, regressing corpora lutea had little or none.

Specificity of uptake of cationic liposomes by angiogenic endothelial cells. The specificity of the uptake of cationic liposomes by angiogenic endothelial cells in tumors and ovaries was assessed by comparing Texas red-labeled DOTAP/choles- 

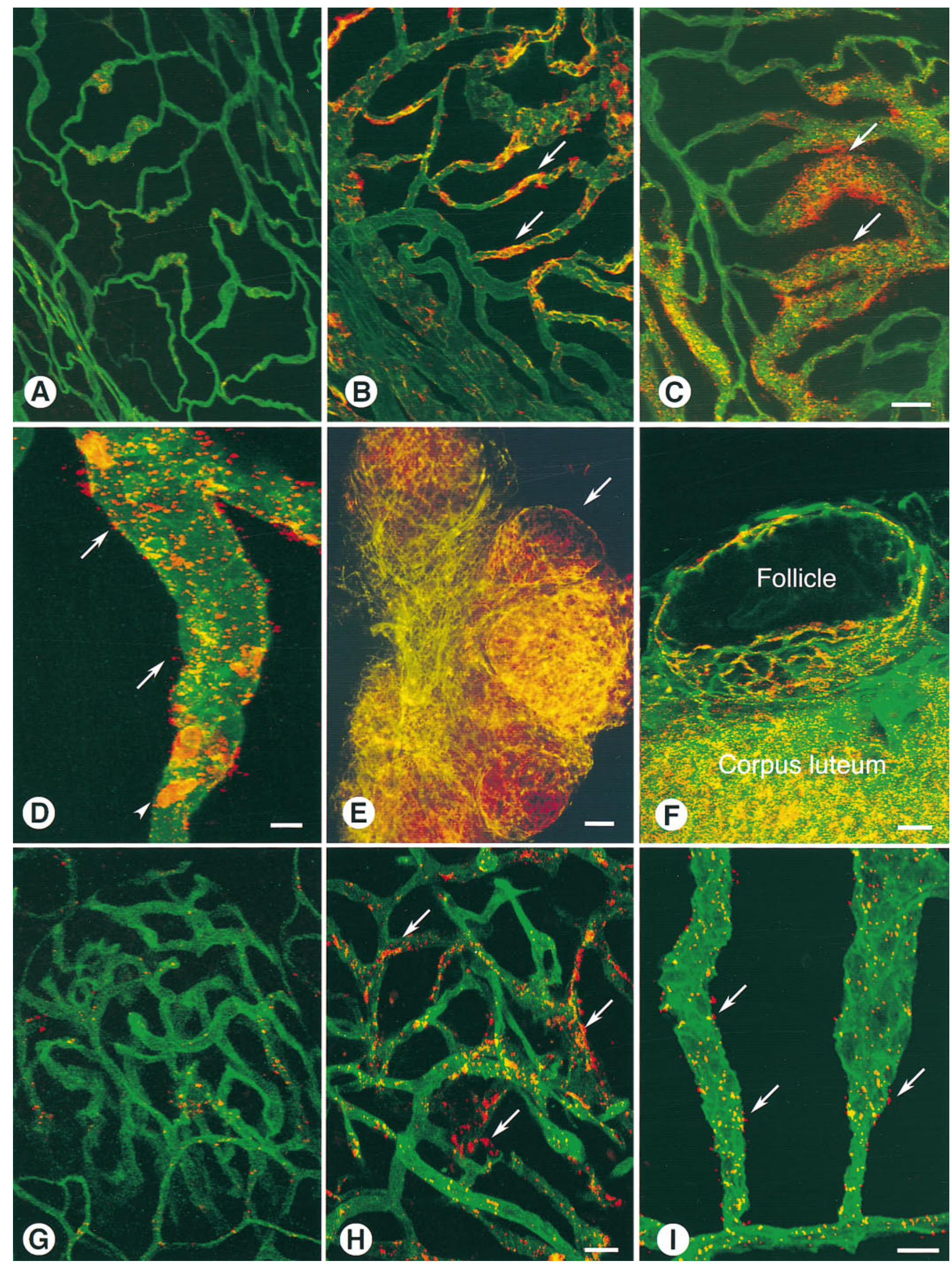
terol cationic liposomes with other liposome formulations. We found no evidence of uptake of Texas red-labeled anionic, neutral, or sterically stabilized neutral liposomes by blood vessels in RIP-Tag2 tumors, ovaries, or other organs at $20 \mathrm{~min}$ after injection.

However, the uptake of Texas red-labeled DOTAP/cholesterol-DNA complexes by angiogenic blood vessels in RIPTag2 tumors and ovaries resembled that of the cationic liposomes. Similarly, liposome-DNA complexes formulated with dimethyldioctadecyl ammonium bromide (DDAB), another cationic lipid, resembled that of free DOTAP/cholesterol liposomes. To determine whether the bright fluorescence of tumor vessels after injection of liposome-DNA complexes indeed reflected the uptake of liposome-DNA complexes and not just the uptake of free liposomes, we injected Cy3-labeled DNA complexed with unlabeled liposomes and examined the distribution of $\mathrm{Cy} 3$ fluorescence in normal islets and tumors of RIPTag2 mice. The tumor vessels had much brighter fluorescence than corresponding normal vessels (Fig. 4, $G$ and $H$ ) and resembled those found after injection of labeled liposomes.

Delivery of macromolecules to angiogenic endothelial cells. The feasibility of using cationic liposomes to deliver macromolecules other than DNA to angiogenic endothelial cells was determined by examining the uptake of liposomeencapsulated Texas red-labeled dextran by tracheal blood vessels in M. pulmonis-infected mice. The uptake of the encapsulated dextran matched that of Texas red-labeled cationic liposomes. At $4 \mathrm{~h}$ after the injection, the encapsulated dextran appeared as abundant fluorescent red dots in the endothelial cells of the angiogenic blood vessels (Fig. $4 I$ ). No red fluorescence was associated with tracheal vessels $4 \mathrm{~h}$ after the injection of free Texas red-labeled dextran without cationic liposomes.

\section{Discussion}

These experiments show that angiogenic blood vessels in tumors of RIP-Tag2 mice and K14-HPV16 mice bound and took up cationic liposomes much more than did the corresponding normal vessels. At $20 \mathrm{~min}$ after injection, most liposomes were on the luminal surface of angiogenic endothelial cells or in multivesicular bodies or vesicles inside the cells. Angiogenic endothelial cells at sites of chronic inflammation in M. pulmonis-infected mice and in normal ovaries also took up cationic liposomes. The magnitude of uptake assessed by confocal microscopy in vessels of tumors and chronically inflamed tracheas was 15-33-fold that of corresponding normal vessels. Angiogenic endothelial cells in these models of angiogenesis also took up cationic liposome-DNA complexes, but not anionic, neutral, or sterically stabilized neutral liposomes. Finally, cationic liposomes were used to deliver fluorescent dextran to angiogenic endothelial cells as a model of macromolecular intracellular delivery.

Endothelial cell uptake versus leakage of cationic liposomes. Plasma leakage is a feature of some angiogenic blood vessels (45-49). Therefore, we sought to determine whether cationic liposomes associate with angiogenic vessels by virtue of binding and uptake by endothelial cells or by virtue of extravasation. Several lines of evidence suggest that the liposome accumulation observed in the models used in this study was primarily by endothelial cell uptake, not by leakage. First, confocal microscopic observations of fluorescent liposomes and lectin-stained vessels showed that the liposomes remained closely associated with the luminal surface of endothelial cells, both in the tumor models and in the infection model. Second, in all models the distribution of the liposomes changed from a diffuse coating of the luminal endothelial cell surface at $20 \mathrm{~min}$ to discrete dots at $4 \mathrm{~h}$, without evidence of appreciable extravasation over time. Third, electron microscopic observations showed that $85 \%$ of the liposomes associated with tumor vessels in RIP-Tag2 mice were attached to the luminal surface of the endothelium or were inside endothelial cells. Only $15 \%$ of the liposomes associated with tumor vessels had crossed the endothelium at $20 \mathrm{~min}$. This evidence of the internalization of liposomes into endosomes is consistent with the change in distribution over time observed by confocal microscopy and fits our previous observations of liposome internalization by certain types of endothelial cells in normal mice (21). Fourth, the avid uptake of liposomes was specific to cationic liposomes and was not observed with anionic, neutral, or sterically stabilized neutral liposomes, whereas sterically stabilized liposomes can extravasate from leaky tumor vessels (25). Addition of DNA to form liposome-DNA complexes did not change this property of cationic liposomes, and the pattern of uptake of liposome-DNA complexes was the same regardless of whether the lipid or the DNA was labeled. Finally, tumor vessels in RIP-Tag2 mice were not abnormally leaky as judged by the limited extravasation of the particulate tracer Monastral blue.

Figure 4. Confocal micrographs showing vessels in mouse trachea $(A-D, I)$, ovary $(E$ and $F)$, pancreatic islet $(G)$, and tumor $(H)$ after intravenous injection of cationic liposomes or liposome-DNA complexes. Vessels stained green with fluorescein L. esculentum lectin. Weak fluorescence from Texas red cationic liposomes (red) in lectin-stained (green) tracheal vessels of pathogen-free mouse $(A)$ compared with bright redorange fluorescence (arrows) in tracheal vessels of $M$. pulmonis-infected mice at $20 \mathrm{~min}(B)$ or $4 \mathrm{~h}(C)$ after injection. $(D)$ Higher magnification of tracheal vessels of $M$. pulmonis-infected mouse $4 \mathrm{~h}$ after injection. Texas red fluorescence in discrete red dots just beneath the luminal surface of endothelium (green), suggestive of intracellular location. Some adherent leukocytes (arrowhead) are also brightly fluorescent. (E) Low magnification fluorescence micrograph of ovary showing bright Texas red fluorescence of cationic liposomes in vessels of follicle (arrow) and corpus luteum (orange structure beneath follicle). $(F)$ Confocal micrograph of ovary showing bright Texas red fluorescence of cationic liposomes in vessel plexus around follicle. Interior of follicle has no fluorescence. Also shown is bright Texas red fluorescence in part of a large corpus luteum. ( $G$ and $H$ ) Confocal micrographs showing Cy3-labeled DNA (red) complexed to nonfluorescent cationic liposomes in lectin-stained pancreatic vessels (green) of RIP-Tag2 mouse $4 \mathrm{~h}$ after intravenous injection. Weak Cy3 fluorescence in vessels of normal-sized islet $(G)$ compared with bright Cy3 fluorescence in tumor vessels $(H$, arrows). (I) Texas red-labeled dextran encapsulated in unlabeled cationic liposomes in tracheal venules of M. pulmonis-infected mouse at $4 \mathrm{~h}$ after injection. Texas red dextran (red, arrows) in discrete dots just beneath luminal surface of lectin stained venule (green), suggestive of intracellular location. Scale bars: $A-C, 50 \mu \mathrm{m} ; D, 12 \mu \mathrm{m} ; E, 200 \mu \mathrm{m} ; F, 50 \mu \mathrm{m} ; G$ and $H, 20$ $\mu \mathrm{m} ; I, 20 \mu \mathrm{m}$. 


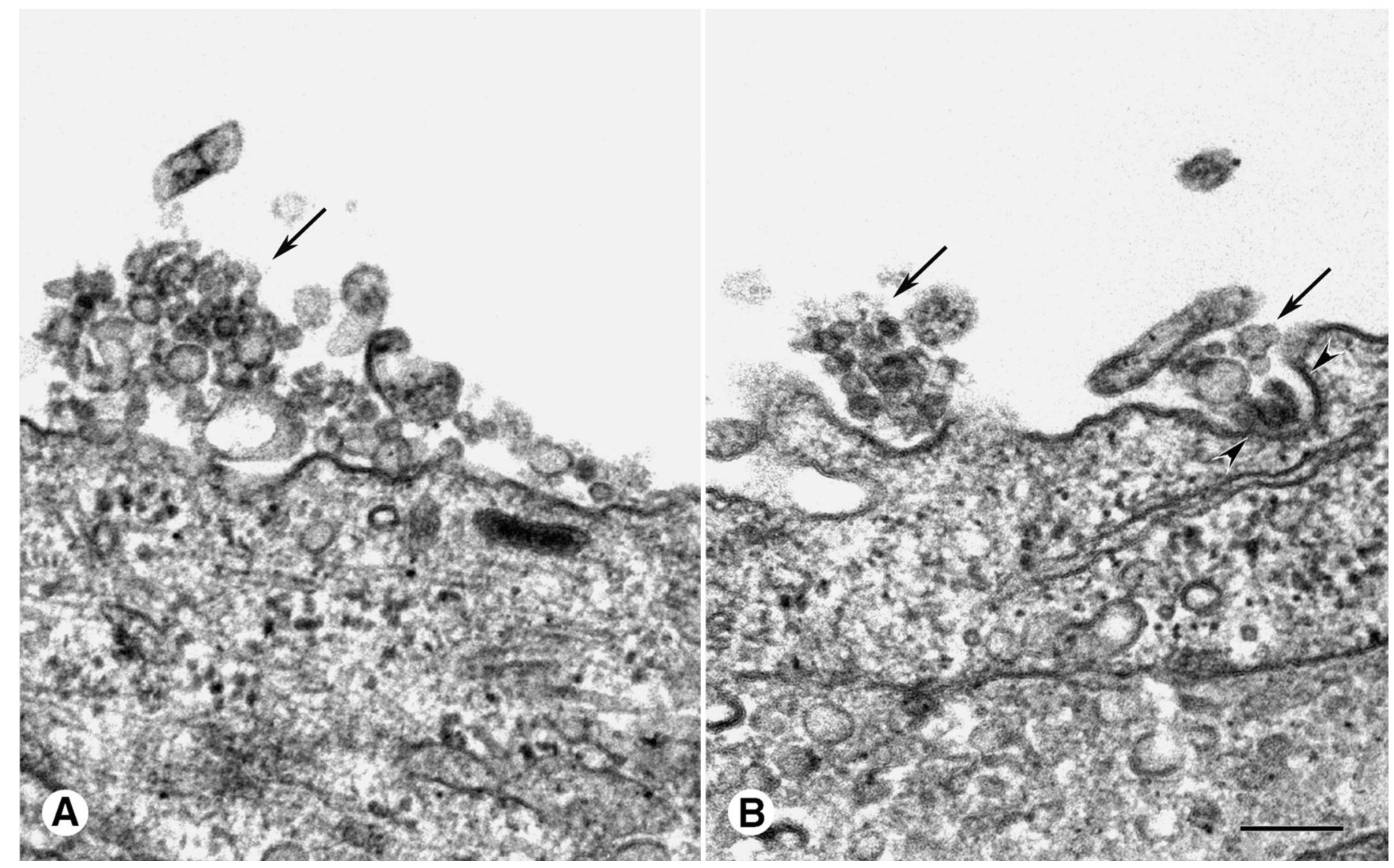

Figure 5. Electron micrographs showing clusters of liposomes (not labeled with gold) adherent on the luminal surface ( $A$ and $B$, arrows) and in a coated invagination ( $B$, arrowheads) of endothelial cells in tracheal vessels of $M$. pulmonis-infected mouse 20 min after injection. Scale bar, $200 \mathrm{~nm}$.

Similarly, the tracheal vasculature of $M$. pulmonis-infected $\mathrm{C} 3 \mathrm{H} / \mathrm{HeNCr}$ mice has about the same amount of plasma leakage as that of pathogen-free rats. ${ }^{2}$

The mechanism by which $15 \%$ of the liposomes in tumors of RIP-Tag2 mice extravasated was not apparent in the electron micrographs. Some liposomes were near the abluminal surface of fenestrae. Although fenestrae are not believed to al-

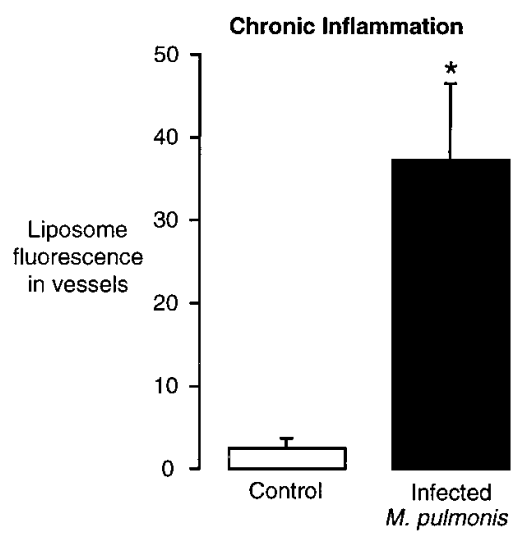

Figure 6. Amount of Texas red fluorescence in tracheal vessels of pathogen-free $\mathrm{C} 3 \mathrm{H} /$ $\mathrm{HeNCr}$ mice and $M$. pulmonis-infected (4 wk) mice $4 \mathrm{~h}$ after injection of Texas redlabeled cationic liposomes. Fluorescence was measured on confocal micrographs of 25 vessels per trachea, 4 mice per group $(n=4)$. Fluorescence values represent digitized sig-

nal (0 to 255) from red channel photomultiplier tube. Values are mean \pm SE. *Significantly different from control value, $P<0.05$, unpaired Student's $t$ test. low passage of particulate or protein tracers $(50,51)$, interactions between the liposomes and the fenestral diaphragms may facilitate such passage. Other mechanisms of leakage, such as endothelial cell gaps or vesicular transport $(49,52)$, could contribute to liposome leakage in tumors of RIP-Tag2 mice, but no intercellular gaps were found in the sections examined by electron microscopy in this study. In other models of angiogenesis, the number of extravasated liposomes would depend on the particular permeability and transcellular transport characteristics of the endothelium and the driving forces in the vasculature.

Mechanism of liposome uptake by endothelial cells. In blood vessels in tumors of RIP-Tag2 mice and tracheas of M. pulmonis-infected mice, liposomes were found on the luminal surface of endothelial cells and inside endothelial cells in small vesicles and multivesicular bodies. Of the 212 silver-enhanced gold-labeled liposomes that we observed inside tumor endothelial cells at $20 \mathrm{~min}$ (out of a total of 400), all appeared to be in vesicular organelles. Some of the liposome-containing vesicles appeared to be coated, suggesting that at least some of the uptake is by endocytosis via clathrin-coated vesicles. Most of the intracellular liposomes were in multivesicular bodies, which may represent a lysosomal compartment (53). Our findings of vesicular uptake of cationic liposomes by endothelial cells in vivo confirm our previous observations (21) and are consistent with reports of endosomal uptake of cationic liposomes in cultured cells $(53,54)$. Our study did not address the 
issue of whether other mechanisms of uptake, such as uptake by noncoated vesicles or liposome-membrane fusion, can also occur.

At 20 min after injection, $51 \%$ of the liposomes on the endothelial cell surface in tumor vessels were associated with fenestrae, although fenestrae constituted only $4 \%$ of the luminal endothelial cell surface. The positive charge of the liposomes may explain their avidity for fenestrae. Cationic ferritin, but not native ferritin, binds to fenestrae, indicating that fenestral diaphragms have a negative charge $(55,56)$.

Despite the preferential adherence of cationic liposomes to endothelial fenestrae in RIP-Tag2 tumors, the avid uptake of cationic liposomes by angiogenic endothelial cells cannot be fully explained by the abundance of fenestrae. First, islet vessels in normal mice had little uptake, despite the presence of fenestrated endothelial cells. Second, avid uptake was also found in tracheal vessels of infected mice, even though these vessels were not fenestrated. Third, intracellular liposomes were found in nonfenestrated regions of endothelial cells, suggesting that fenestrae are not necessary for vesicular uptake. Fourth, large differences in the amount of uptake are present among fenestrated vessels in different organs, such as the thyroid, anterior pituitary, posterior pituitary, and pancreatic islets (21).

Thus, mechanisms of binding other than the affinity of cationic liposomes for fenestrae must be important. One possibility is that liposome binding and internalization by nonfenestrated regions of the plasma membrane is receptor mediated, while binding to fenestrae is by nonspecific charge interaction and does not result in internalization. Because of the rapidity of the internalization, an examination of the binding distribution at earlier times after injection could help to determine the relative contributions of binding to fenestrated and nonfenestrated regions of endothelial cells.

Identification of sites of uptake of cationic liposomes. Cationic liposomes and liposome-DNA complexes are rapidly cleared from the bloodstream with a half-life of $<5$ min (29). This clearance results predominantly from the rapid uptake by macrophages in the liver and spleen and by endothelial cells in an organ- and vessel-specific pattern (21). Endothelial cells in capillaries of the lung and anterior pituitary avidly bind and take up cationic liposomes, as do those in high endothelial venules of lymph nodes, while endothelial cells in many other sites, including pancreatic islets and trachea, take up few liposomes.

In this study, the avid uptake of cationic liposomes by angiogenic endothelial cells in mice with tumors or chronic airway inflammation was superimposed on the normal pattern of uptake (21). The liver, spleen, and lung were still the principal sites of uptake, because of their large size in comparison to that of the tumors or inflamed airways. Modification of the surface properties of cationic liposomes or addition of specific targeting molecules may make it possible to increase the uptake by angiogenic endothelial cells or decrease the uptake by normal endothelial cells and macrophages.

Most of the blood vessels in RIP-Tag2 tumors form during an $\sim 3$-4-wk period of rapid tumor growth (31), during which tumor volume increases by several orders of magnitude. Similarly, most of the vessels of enlarging ovarian follicles and corpora lutea form while these structures are growing rapidly. Because newly formed blood vessels predominate in these systems, most of the avid uptake of cationic liposomes is by new endothelial cells. This issue is not as straightforward for the model of $M$. pulmonis infection in $\mathrm{C} 3 \mathrm{H} / \mathrm{HeNCr}$ mice, where the blood vessels of the tracheal mucosa enlarge but do not become more numerous. In this case, the uptake is evidently by endothelial cells within existing vessels that enlarge (17). It is not yet known whether the avid uptake coincides temporally with the proliferation of the endothelial cells.

Heterogeneity of endothelial cells in angiogenic vessels. The avid uptake of liposomes was not uniformly distributed. In RIP-Tag2 mice, focal regions of vessels in hyperplastic islets (31) had an unusually high uptake. Furthermore, some of these foci were located in vessel sprout-like protrusions that ended blindly. In contrast, uptake was uniformly high in the vasculature of large tumors. In $M$. pulmonis-infected mice, the avid uptake was confined to particular segments of the microvasculature, in the position of postcapillary venules and collecting venules, but even here, the uptake was much higher in some vessels than others.

The presence of focal sites of avid liposome uptake raises the possibility of a novel heterogeneity among endothelial cells of newly formed or remodeled vessels. Because the uptake by vessels in hyperplastic islets and small tumors of RIP-Tag2 mice tended to be focal, whereas that in large tumors was uniform, the switch in uptake may occur at an early stage in the angiogenic process. It is unknown how these sites of uptake relate to the presumptive processes that occur during angiogenesis, for example, endothelial cell proliferation, migration, basement membrane remodeling, lumen formation, and vessel maturation (2).

Various phenotypic markers of angiogenic endothelial cells, including the integrin $\alpha_{v} \beta_{3}(5)$, the profile of cell surface oligosaccharides (7), vascular endothelial growth factor receptors (6), and other cell surface proteins (4), have been reported in particular systems of angiogenesis. An important next step will be to determine whether these phenotypic markers define the same population of endothelial cells as does the avid uptake of cationic liposomes. If not, multiple endothelial cell phenotypes may participate in angiogenesis, and the concept of an angiogenic endothelial cell may require expansion (57). A precedent for such cell heterogeneity is the report that migrating endothelial cells are primarily at the leading tip of a vascular sprout while proliferating cells are at the base (58).

Although liposomes were avidly taken up by endothelial cells in all of the models of angiogenesis we examined, these observations need not apply to all other models of angiogenesis. We intentionally used models of diseases in which angiogenesis occurs, with the long-term aim of altering the disease progression by reversing the angiogenesis. However, the signals that induce angiogenesis in these systems are likely to be complex, and the process of vessel growth has not been fully characterized. It may be necessary to use simpler models of angiogenesis to elucidate the endothelial cell mechanisms, relevant signaling molecules, and particular stages of vessel growth involved in the uptake of cationic liposomes by angiogenic endothelial cells.

Using cationic liposomes to target agents to angiogenic endothelial cells. The preferential uptake of cationic liposomes raises the possibility of delivering diagnostic or therapeutic agents to growing or remodeling blood vessels. This approach differs conceptually from previous approaches of liposomemediated delivery that targeted tumor cells directly by exploiting the increased permeability of tumor vessels to achieve 
higher drug concentrations near tumor cells $(25,27)$. One of the problems of using endothelial cell leakiness to deliver agents to tumors is that a high interstitial pressure may limit the convective movement of molecules from the vessel lumen into the tumor interstitium (52). In comparison, cationic liposomes would deliver substances to the endothelium as long as there is blood flow, and delivery would not depend on convective movement across the vessel wall. Thus, cationic liposomes could be used to deliver agents to angiogenic endothelial cells rather than to tumor or interstitial cells.

Strategies of delivering substances selectively to angiogenic endothelial cells include targeting specific growth factor receptors (4), upregulated coagulant factors $(59,60)$, and key cell adhesion proteins (61). The avid uptake of cationic liposomes by angiogenic endothelial cells described here may provide a new tool to deliver diagnostic or therapeutic agents to these cells. For example, substances that initiate coagulation and stasis in tumor vessels could be targeted transiently to the luminal surface of the endothelium (10). Alternatively, drugs, toxins, or antisense oligonucleotides could be delivered intracellularly by endocytosis. In addition, plasmids encoding appropriate transgenes could be complexed to cationic liposomes and delivered to angiogenic endothelial cells for expression. Indeed, transgene expression mediated by cationic liposome-DNA complexes may have antitumor effects (62). For diagnostic purposes, fluorescent or radiopaque tracers could be incorporated into cationic liposomes and used to mark sites of angiogenesis. Future studies can explore the utility of using cationic liposomes to deliver substances to tumor endothelial cells and develop tools to modulate angiogenesis in tumors, chronic inflammation, and other diseases.

We conclude that endothelial cells in angiogenic blood vessels in the models we examined avidly take up cationic liposomes and cationic liposome-DNA complexes by endocytosis. The amount of uptake is considerably greater than the amount of extravasation from these vessels. This uptake is selective to cationic liposomes in that anionic, neutral, or sterically stabilized neutral liposomes are not taken up by these cells. This property of angiogenic endothelial cells provides an approach to deliver substances to these cells for diagnosis or therapy. One particular application may be the use cationic liposomemediated gene therapy to target expression of antiangiogenic transgenes to endothelial cells of tumor vessels.

\section{Acknowledgments}

The authors thank Dr. J. Russell Lindsey and Ms. Julie Erwin for supplying the M. pulmonis organisms and advice for infecting mice, Dr. Lisa Coussens for supplying the K14-HPV16 transgenic mice, Mr. Eric Umemoto for assistance with animal perfusions, and Ms. Evelyn Clausnitzer for cutting Vibratome sections.

This work was supported in part by National Institutes of Health Program Project grant HL-24136.

\section{References}

1. Folkman, J. 1995. Angiogenesis in cancer, vascular, rheumatoid and other disease. Nat. Med. 1:27-31.

2. Folkman, J. 1992. The role of angiogenesis in tumor growth. Semin. Cancer Biol. 3:65-71.

3. Denekamp, J. 1984. Vascular endothelium as the vulnerable element in tumours. Acta Radiol. Oncol. 23:217-225.

4. Thorpe, P.E., and F.J. Burrows. 1995. Antibody-directed targeting of the vasculature of solid tumors. Breast Cancer Res. Treat. 36:237-251.
5. Brooks, P.C., R.A. Clark, and D.A. Cheresh. 1994. Requirement of vascular integrin $\alpha_{\mathrm{v}} \beta_{3}$ for angiogenesis. Science. 264:569-571.

6. Qu, H., J.A. Nagy, D.R. Senger, H.F. Dvorak, and A.M. Dvorak. 1995. Ultrastructural localization of vascular permeability factor/vascular endothelial growth factor (VPF/VEGF) to the abluminal plasma membrane and vesiculovacuolar organelles of tumor microvascular endothelium. J. Histochem. Cytochem. 43:381-389.

7. Augustin, H.G., K. Braun, I. Telemenakis, U. Modlich, and W. Kuhn. 1995. Ovarian angiogenesis. Phenotypic characterization of endothelial cells in a physiological model of blood vessel growth and regression. Am. J. Pathol. 147: 339-351.

8. Brooks, P.C., S. Stromblad, R. Klemke, D. Visscher, F.H. Sarkar, and D.A. Cheresh. 1995. Antiintegrin alpha v beta 3 blocks human breast cancer growth and angiogenesis in human skin. J. Clin. Invest. 96:1815-1822.

9. Yuan, F., Y. Chen, M. Dellian, N. Safabakhsh, N. Ferrara, and R.K. Jain. 1996. Time-dependent vascular regression and permeability changes in established human tumor xenografts induced by an anti-vascular endothelial growth factor/vascular permeability factor antibody. Proc. Natl. Acad. Sci. USA. 93: $14765-14770$.

10. Huang, X., G. Molema, S. King, L. Watkins, T.S. Edgington, and P.E. Thorpe. 1997. Tumor infarction in mice by antibody-directed targeting of tissue factor to tumor vasculature. Science. 275:547-550.

11. Patan, S., L.L. Munn, and R.K. Jain. 1996. Intussusceptive microvascular growth in a human colon adenocarcinoma xenograft: a novel mechanism of tumor angiogenesis. Microvasc. Res. 51:260-272.

12. Fukumura, D., F. Yuan, W.L. Monsky, Y. Chen, and R.K. Jain. 1997. Effect of host microenvironment on the microcirculation of human colon adenocarcinoma. Am. J. Pathol. 151:679-688.

13. Dellian, M., B.P. Witwer, H.A. Salehi, F. Yuan, and R.K. Jain. 1996. Quantitation and physiological characterization of angiogenic vessels in mice: effect of basic fibroblast growth factor, vascular endothelial growth factor/vascular permeability factor, and host microenvironment. Am. J. Pathol. 149:59-71.

14. McDonald, D.M., T.R. Schoeb, and J.R. Lindsey. 1991. Mycoplasma pulmonis infections cause long-lasting potentiation of neurogenic inflammation in the respiratory tract of the rat. J. Clin. Invest. 87:787-799.

15. Joris, I., H.F. Cuenoud, J.M. Underwood, and G. Majno. 1992. Capillary remodeling in acute inflammation: a form of angiogenesis. FASEB (Fed. Am. Soc. Exp. Biol.) J. 6:A938. (Abstr.)

16. Baluk, P., J.J. Bowden, P.M. Lefevre, and D.M. McDonald. 1997. Upregulation of substance $\mathrm{P}$ receptors in angiogenesis associated with chronic airway inflammation in rats. Am. J. Physiol. 273:L565-L571.

17. Murphy, T.J., G. Thurston, J. Erwin, J.R. Lindsey, and D.M. McDonald. 1997. Vascular remodeling in chronic inflammation of mouse airways. Am. J. Respir. Crit. Care Med. 155:A124. (Abstr.)

18. Brigham, K.L., B. Meyrick, B. Christman, M. Magnuson, G. King, and L.C. Berry, Jr. 1989. In vivo transfection of murine lungs with a functioning prokaryotic gene using a liposome vehicle. Am. J. Med. Sci. 298:278-281.

19. Canonico, A.E., J.T. Conary, B.O. Meyrick, and K.L. Brigham. 1994. Aerosol and intravenous transfection of human alpha 1-antitrypsin gene to lungs of rabbits. Am. J. Respir. Cell Mol. Biol. 10:24-29.

20. Zhu, N., D. Liggitt, Y. Liu, and R. Debs. 1993. Systemic gene expression after intravenous DNA delivery into adult mice. Science. 261:209-211.

21. McLean, J.W., E.A. Fox, P. Baluk, P.B. Bolton, A. Haskell, R. Pearlman, G. Thurston, E.Y. Umemoto, and D.M. McDonald. 1997. Organ-specific endothelial cell uptake of cationic liposome-DNA complexes in mice. Am. J. Physiol. 273:H387-H404.

22. Mayer, L.D., L.C. Tai, D.S. Ko, D. Masin, R.S. Ginsberg, P.R. Cullis, and M.B. Bally. 1989. Influence of vesicle size, lipid composition, and drugto-lipid ratio on the biological activity of liposomal doxorubicin in mice. Cancer Res. 49:5922-5930.

23. Papahadjopoulos, D., T.M. Allen, A. Gabizon, E. Mayhew, K. Matthay, S.K. Huang, K.D. Lee, M.C. Woodle, D.D. Lasic, C. Redemann, and F.J. Martin. 1991. Sterically stabilized liposomes: improvements in pharmacokinetics and antitumor therapeutic efficacy. Proc. Natl. Acad. Sci. USA. 88:11460-11464.

24. Huang, S.K., E. Mayhew, S. Gilani, D.D. Lasic, F.J. Martin, and D. Papahadjopoulos. 1992. Pharmacokinetics and therapeutics of sterically stabilized liposomes in mice bearing C-26 colon carcinoma. Cancer Res. 52:6774-6781.

25. Yuan, F., M. Leunig, S.K. Huang, D.A. Berk, D. Papahadjopoulos, and R.K. Jain. 1994. Microvascular permeability and interstitial penetration of sterically stabilized (stealth) liposomes in a human tumor xenograft. Cancer Res. 54:3352-3356.

26. Huang, S.K., K.D. Lee, K. Hong, D.S. Friend, and D. Papahadjopoulos. 1992. Microscopic localization of sterically stabilized liposomes in colon carcinoma-bearing mice. Cancer Res. 52:5135-5143.

27. Wu, N.Z., D. Da, T.L. Rudoll, D. Needham, A.R. Whorton, and M.W. Dewhirst. 1993. Increased microvascular permeability contributes to preferential accumulation of Stealth liposomes in tumor tissue. Cancer Res. 53:37653770 .

28. Mahato, R.I., K. Kawabata, T. Nomura, Y. Takakura, and M. Hashida. 1995. Physicochemical and pharmacokinetic characteristics of plasmid DNA/ cationic liposome complexes. J. Pharm. Sci. 84:1267-1271.

29. Litzinger, D.C., J.M. Brown, I. Wala, S.A. Kaufman, G.Y. Van, C.L. 
Farrell, and D. Collins. 1996. Fate of cationic liposomes and their complex with oligonucleotide in vivo. Biochim. Biophys. Acta. 1281:139-149.

30. Hanahan, D. 1985. Heritable formation of pancreatic beta-cell tumours in transgenic mice expressing recombinant insulin/simian virus 40 oncogenes. Nature. 315:115-122.

31. Hanahan, D., and J. Folkman. 1996. Patterns and emerging mechanisms of the angiogenic switch during tumorigenesis. Cell. 86:353-364.

32. Folkman, J., K. Watson, D. Ingber, and D. Hanahan. 1989. Induction of angiogenesis during the transition from hyperplasia to neoplasia. Nature. 339: $58-61$.

33. Parangi, S., M. O’Reilly, G. Christofori, L. Holmgren, J. Grosfeld, J. Folkman, and D. Hanahan. 1996. Antiangiogenic therapy of transgenic mice impairs de novo tumor growth. Proc. Natl. Acad. Sci. USA. 93:2002-2007.

34. Arbeit, J.M., K. Munger, P.M. Howley, and D. Hanahan. 1994. Progressive squamous epithelial neoplasia in K14-human papilloma virus type 16 transgenic mice. J. Virol. 68:4358-4368.

35. Coussens, L.M., D. Hanahan, and J.M. Arbeit. 1996. Genetic predisposition and parameters of malignant progression in K14-HPV16 transgenic mice. Am. J. Pathol. 149:1899-1917.

36. Cartner, S.C., J.W. Simecka, J.R. Lindsey, G.H. Cassell, and J.K. Davis. 1995. Chronic respiratory mycoplasmosis in $\mathrm{C} 3 \mathrm{H} / \mathrm{HeN}$ and C57BL/6N mice: lesion severity and antibody response. Infect. Immun. 63:4138-4142.

37. Dunnill, M.S. 1960. The pathology of asthma, with special references to changes in the bronchial mucosa. J. Clin. Pathol. 13:27-33.

38. Kuwano, K., C.H. Bosken, P.D. Pare, T.R. Bai, B.R. Wiggs, and J.C. Hogg. 1993. Small airways dimensions in asthma and in chronic obstructive pulmonary disease. Am. Rev. Respir. Dis. 148:1220-1225.

39. Carroll, N.G., C. Cooke, and A.L. James. 1997. Bronchial blood vessel dimensions in asthma. Am. J. Respir. Crit. Care Med. 155:689-695.

40. Li, X., and J.W. Wilson. 1997. Increased vascularity of the bronchial mucosa in mild asthma. Am. J. Respir. Crit. Care Med. 156:229-233.

41. Gordon, J.D., J.L. Shifren, R.A. Foulk, R.N. Taylor, and R.B. Jaffe. 1995. Angiogenesis in the human female reproductive tract. Obstet. Gynecol. Survey. 50:688-697.

42. Shweiki, D., A. Itin, G. Neufeld, H. Gitay-Goren, and E. Keshet. 1993. Patterns of expression of vascular endothelial growth factor (VEGF) and VEGF receptors in mice suggest a role in hormonally regulated angiogenesis. $J$. Clin. Invest. 91:2235-2243.

43. Burry, R.W., D.D. Vandre, and D.M. Hayes. 1992. Silver enhancement of gold antibody probes in pre-embedding electron microscopic immunocytochemistry. J. Histochem. Cytochem. 40:1849-1856.

44. McDonald, D.M. 1994. Endothelial gaps and permeability of venules in rat tracheas exposed to inflammatory stimuli. Am. J. Physiol. 266:L61-L83.

45. Schoefl, G.I. 1963. Studies on inflammation. III. Growing capillaries. Their structure and permeability. Virchows Arch. Path. Anat. 337:97-141.

46. Jain, R.K., and L.E. Gerlowski. 1986. Extravascular transport in normal and tumor tissues. Crit. Rev. Oncol. Hematol. 5:115-170.

47. Jain, R.K. 1987. Transport of molecules in the tumor interstitium: a review. Cancer Res. 47:3039-3051.
48. Yuan, F., H.A. Salehi, Y. Boucher, U.S. Vasthare, R.F. Tuma, and R.K. Jain. 1994. Vascular permeability and microcirculation of gliomas and mammary carcinomas transplanted in rat and mouse cranial windows. Cancer Res. $54: 4564-4568$

49. Dvorak, H.F., L.F. Brown, M. Detmar, and A.M. Dvorak. 1995. Vascular permeability factor/vascular endothelial growth factor, microvascular hyperpermeability, and angiogenesis. Am. J. Pathol. 146:1029-1039.

50. Pino, R.M. 1985. Restriction to endogenous plasma proteins by a fenestrated capillary endothelium: an ultrastructural immunocytochemical study of the choriocapillary endothelium. Am. J. Anat. 172:279-289.

51. Pino, R.M., and E. Essner. 1981. Permeability of rat choriocapillaries to hemeproteins. Restriction of tracers by a fenestrated endothelium. J. His tochem. Cytochem. 29:281-290.

52. Jain, R.K. 1987. Transport of molecules across tumor vasculature. Cancer Metastasis Rev. 6:559-593.

53. Friend, D.S., D. Papahadjopoulos, and R.J. Debs. 1996. Endocytosis and intracellular processing accompanying transfection mediated by cationic liposomes. Biochim. Biophys. Acta 1278:41-50.

54. Zabner, J., A.J. Fasbender, T. Moninger, K.A. Poellinger, and M.J. Welsh. 1995. Cellular and molecular barriers to gene transfer by a cationic lipid. J. Biol. Chem. 270:18997-19007.

55. Bankston, P.W., and A.J. Milici. 1983. A survey of the binding of polycationic ferritin in several fenestrated capillary beds: indication of heterogeneity in the luminal glycocalyx of fenestral diaphragms. Microvasc. Res. 26:36-48.

56. Milici, A.J., N. L'Hernault, and G.E. Palade. 1985. Surface densities of diaphragmed fenestrae and transendothelial channels in different murine capillary beds. Circ. Res. 56:709-717.

57. Augustin, H.G., D.H. Kozian, and R.C. Johnson. 1994. Differentiation of endothelial cells: analysis of the constitutive and activated endothelial cell phenotypes. Bioessays. 16:901-906.

58. Ausprunk, D.H., and J. Folkman. 1977. Migration and proliferation of endothelial cells in preformed and newly formed blood vessels during tumor angiogenesis. Microvasc. Res. 14:53-65.

59. Nawroth, P., D. Handley, G. Matsueda, R. De Waal, H. Gerlach, D. Blohm, and D. Stern. 1988. Tumor necrosis factor/cachectin-induced intravascular fibrin formation in meth A fibrosarcomas. J. Exp. Med. 168:637-647.

60. Murray, J.C., M. Clauss, J. Denekamp, and D. Stern. 1991. Selective in duction of endothelial cell tissue factor in the presence of a tumour-derived mediator: a potential mechanism of flavone acetic acid action in tumour vasculature. Int. J. Cancer. 49:254-259.

61. Brooks, P.C., A.M. Montgomery, M. Rosenfeld, R.A. Reisfeld, T. Hu, G. Klier, and D.A. Cheresh. 1994. Integrin alpha v beta 3 antagonists promote tumor regression by inducing apoptosis of angiogenic blood vessels. Cell. 79: $1157-1164$.

62. Xu, M., D. Kumar, S. Srinivas, L.J. Detolla, S.F. Yu, S.A. Stass, and A.J. Mixson. 1997. Parental gene therapy with p53 inhibits human breast tumors in vivo through a bystander mechanism without evidence of toxicity. Hum. Gene Ther. 8:177-185. 